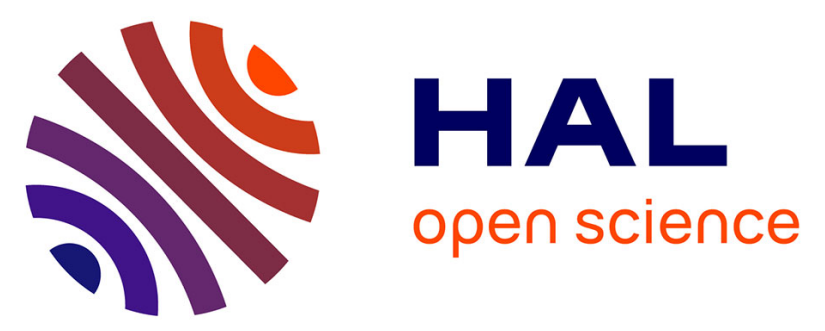

\title{
Physically based coupled model for simulating 1D surface-2D subsurface flow and plant water uptake in irrigation furrows. II: Model test and evaluation
}

T. Wöhling, J.C. Mailhol

\section{- To cite this version:}

T. Wöhling, J.C. Mailhol. Physically based coupled model for simulating 1D surface-2D subsurface flow and plant water uptake in irrigation furrows. II: Model test and evaluation. Journal of Irrigation and Drainage Engineering, 2007, 133 (6), p. 543 - p. $553 . \quad 10.1061 /(\mathrm{ASCE}) 0733-$ 9437(2007)133:6(548) . hal-00453854

\section{HAL Id: hal-00453854 https://hal.science/hal-00453854}

Submitted on 5 Feb 2010

HAL is a multi-disciplinary open access archive for the deposit and dissemination of scientific research documents, whether they are published or not. The documents may come from teaching and research institutions in France or abroad, or from public or private research centers.
L'archive ouverte pluridisciplinaire HAL, est destinée au dépôt et à la diffusion de documents scientifiques de niveau recherche, publiés ou non, émanant des établissements d'enseignement et de recherche français ou étrangers, des laboratoires publics ou privés. 


\title{
A Physically Based Coupled Model for Simulating 1D Surface - 2D Subsurface Flow and Plant Water Uptake in Irrigation Furrows. II: Model Test and Evaluation
}

\author{
Th. Wöhling*, J.C. Mailhol ${ }^{\dagger}$
}

\begin{abstract}
A physically based seasonal furrow irrigation model - FIM - was developed which comprises three modules: the $1 \mathrm{D}$ surface flow, the 2D subsurface flow and and a crop model. The modeling principles of these modules, their simultaneous coupling and the solution strategies were described in a companion paper: I Model development. In the current contribution, we present the model testing with experimental data from five real-scale laboratory experiments (HEL), two field experiments in Kharagpur, Eastern India (KGP), one literature data set (FW), and data from three irrigations during a corn growing season in Montpellier, Southern France (LAT). The simulated irrigation advance times match well with the observations of the HEL, FW and KGP experiments which is confirmed by coefficients of determination $R^{2} \geq 0.99$ and coefficients of efficiency $C_{e} \geq 0.7$. Predicted recession times also match with the observations of the HEL runs, however, the values of $R^{2} \geq 0.9$ and $C_{e} \geq 0.6$ are lower for predicted recession times as compared to predicted advance times. In contrast to the other experiments in the study, advance times are under predicted for the experiments in France. The established soil hydraulic parameters for this site lead to an underestimation of the actual initial infiltration capability of the soil. In the long-term simulation, however, the overall change in soil moisture storage is correctly predicted by the model and the calculated yield of $12.8 t h a^{-1}$ is in very good agreement with the observations $\left(12.7 t h a^{-1}\right)$. We evaluated the sensitivity of the input parameters with regards to predicted advance time and runoff in both a $26.4 \mathrm{~m}$ long furrow and a long $360 \mathrm{~m}$ long furrow. The analysis revealed that calculated runoff is four to five times more sensitive to the inlet flow rate than to infiltration parameters. Furrow geometry parameters are most sensitive to calculated advance times in the short furrow with low infiltration opportunity time, whereas the inflow rate and infiltration parameters are more sensitive to calculated advance times in the long furrow with larger infiltration opportunity time.
\end{abstract}

\footnotetext{
${ }^{*}$ Corresponding author: Research Hydrologist, Lincoln Environmental Research, Hamilton, New Zealand. Email: woehling@lvlham.lincoln.ac.nz

†Irrigation Research Unit Cemagref BP 5095, 34033 Montpellier Cedex 1, France.
} 
Keywords: Furrow Irrigation, Infiltration, Two-dimensional models, Mathematical models, Coupling, Overland flow, Subsurface flow 


\section{Introduction}

In spite of the increasing power of standard computers, empirical approaches offer still todays solutions to the challenge of modeling the water movement processes in irrigation systems. These empirical approaches can provide efficient solutions to practitioners when predicting cumulative infiltration and the rate of infiltration. But they cannot simulate the movement and redistribution of water once in the soil. In addition, parameter estimates are event specific, hence cannot account for the effects of changes in flow depth and antecedent soil moisture content on infiltration. This limits the flexibility and accuracy of empirical infiltration functions when used over a range of irrigation conditions. Nevertheless, due to a lack of costly and time consuming field trials, their area of validity is not always well defined and, consequently, there is a natural tendency to unreasonably extend the validity domain of the empirical approaches. One such attempt is to empirically correct the infiltration in order to account for flow depth variations. But it does not overcome the limitations of empirical formulas. In addition, it is difficult to select the most appropriate formula and coefficient amongst the series of correction formulas proposed by literature (Oyonarte et al. 2002; Alvarez 2003). In general, the use of empirical infiltration formulas should be limited to conditions under which their parameter were identified (Haverkamp et al. 1988). This limitation also restricts the alternatives to optimise a furrow irrigation system. Indeed, the impact of irrigation management on the performance of the system cannot be simulated because the soil water depletion resulting from a specific irrigation shedule (frequency of irrigation events) is not mathematically linked to these equations. At last, it seems interesting to verify if an irrigation strategy inducing water saving can also ensure a satisfactory yield level on a given climatic scenario. Mechanistical model approaches, on the other side, describe the interrelated processes by suitable mathematical relationships and therefore allow the extension of the validity domain without a complement of experimental data. Therefore, they can yield accurate estimates of irrigation performance for both irrigation events and on a seasonal basis under a variety of management strategies.

The principles of the FIM model - which is used in this study - were described in the companion paper "A physically based coupled model for simulating 1D surface - 2D subsurface flow and plant water uptake in irrigation furrows. I: Model development". The three main modules of FIM are: the surface flow model, the HYDRUS-2 subsurface flow model and the crop model. The model components, their interactions, preprocessing routines and postprocessing routines are controlled by an overall time control and event management, which forms the framework of FIM. Although physically based, the governing equations of the subsurface flow model are limited to the simulation of processes in the soil matrix which impairs the accuracy of FIM in the presence of macro-pores. It is well known that under cropped soils, where the macro pore effect can be dominant, the assumption of Darcian flux is not appropriate, especially in the case of cracking soils (Mailhol and Gonzalez 1993; Mailhol et al. 1999). Even when we exclude soils for which perferential flow invalidates 
FIM, we do not have the guaranty to simulate correctly the different phases of an irrigation event with soil hydraulic parameters obtained from either a pedo-transfer function (Schaap and Leij 1998); or laboratory analysis of a limited number of soil samples; or local infiltration tests (Vachaud et al. 1978; Peroux and White 1988). If these methods are used to estimate soil parameter values, then they have to be validated or, if necessary, adapted to the furrow irrigation field context. After model test and validation with representative experimental data FIM can be used to identify the impact of irrigation design and management parameters on water use efficiency and crop yield. The aim of this paper is to test and validate FIM on various data sets. First studies on combining FIM with new optimization methods, such as artificial neuronal networks (ANN) and genetic algorithms, revealed a high potential to significantly increase furrow irrigation efficiency by optimizing both the scheduling and the irrigation parameters (Schmitz et al. 2006).

\section{Experimental Data}

(1) Furrow irrigation experiments were conducted on $40 \mathrm{~m}$ long furrows of sandy loam soil (20\% silt, $65 \%$ sand, $15 \%$ clay) at the experimental plot of the Indian Institute of Technology (IIT) Kharagpur, India. The furrow slope, the inter-furrow spacing and the roughness coefficient were $S_{0}=0.005 \mathrm{~m} \mathrm{~m}^{-1}, f_{s}=0.75 \mathrm{~m}$ and $K=$ $25 \mathrm{~m}^{1 / 3} \mathrm{~s}^{-1}$, respectively (REFERENCE VW BERICHT). The furrow geometry parameters were derived from measurements before each irrigation. Soil hydraulic parameters were derived from laboratory analysis of soil samples and local infiltration tests. Soil moisture data (TDR probes) and tesiometric data were recorded at $0.5,13,26$ and $39 \mathrm{~m}$ distance along the furrow at four depths. The parameter sets the runs KGP-1 and KGP-5 are listed in Tables 1, 2 and 3. Further details on the experiments were given in Wöhling et al. (2006).

(2) In order to include a relatively long field in this analysis, the "Flowell wheel" (FW) run was selected from a study by Walker and Humpherys (1983). This run was conducted on a $360 \mathrm{~m}$ long field of sandy loam (Texture) with a slope of $S_{0}=0.008 \mathrm{~m} \mathrm{~m}^{-1}$. The soil hydraulic parameters are estimated from textural field data using the Rossetta database and a HYDRUS-2 parameter calibration with respect to calculated cumulative infiltration (Wöhling et al. 2006). The calibration is based on the assumption of homogeneous initial pressure head of $h_{w}=-10 \mathrm{~m}$ and and a gradually increasing pressure head within the upper soil layer of $0.1 \mathrm{~m}$ to $h_{w}=-200 \mathrm{~m}$ at the surface (soil evaporation) in a $0.8 \times 2.0 \mathrm{~m}$ modeling domain. Soil hydraulic parameters were adapted in the calibration to match the simulated (HYDRUS-2) and the measured cumulative infiltration. The hydraulic section parameters $p_{1} . . p_{4}$ were derived mathematically from the profile functions given in Walker and Humpherys (1983). The set of parameters is given in Tables 1 and 2 .

(3) Furrow irrigation experiments were conducted at the Hubert-Engels Laboratory of the Institute of Hy- 
draulic Engineering and Applied Hydromechanics, Dresden University of Technology (Germany). The experiments were conducted in a $26.4 \mathrm{~m}$ long, $0.88 \mathrm{~m}$ wide and $1.0 \mathrm{~m}$ deep experimental tank equipped with 50 tensiometer probes at five cross-sections. The experiments on silty loam (60\% silt, $30 \%$ sand, $10 \%$ clay) reported in earlier studies (Wöhling et al. 2004, 2006) focused on measurements of the irrigation advance phase only. Another set of experiments was conducted on sandy loam (18\% silt, $72 \%$ sand, 10\% clay) at the same laboratory set up. Soil hydraulic parameters of the van-Genuchten-Mualem model (VGM) were determined from lab analysis of soil samples at $2 m, 12 m$, and $24 m$ furrow distance (Table 2). Initial infiltration tests suggested a saturated hydraulic conductivity of about $K_{s}=2.05 \cdot 10^{-5} \mathrm{~m} \mathrm{~s}^{-1}$, which is about twice as much as estimated by the laboratory analysis but in agreement with data from the Rossetta database for this type. Hence this value is used in this study. The furrow geometry parameters are derived from measurements before and after each irrigation by mathematical fitting (nonlinear unconstraint optimization with the Nelder-Mead Simplex Method). These geometry parameters and the irrigation parameters of the runs HEL-71, HEL-72, HEL-8, HEL-91, HEL-91, and HEL-11 are listed in Table 1. The initial pressure head in the soil was calculated from tensiometer readings which were averaged over five cross sections (Table 3). HEL-72 and HEL-92 are irrigations following an initial run (HEL-71 and HEL-91, respectively) after a relatively short time (HEL-72: 42min, HEL-92: 8.3min). The initial conditions for these runs are subject to model prediction and therefore not included in the list.

The roughness coefficient $K_{s t}=25 \mathrm{~m}^{1 / 3} \mathrm{~s}^{-1}$ was calibrated with the data of the HEL-8 run (not used for model validation). The calibrated roughness coefficient was used for parameterization of the other HEL experiments with one exception: In contrast to the field conditions, where the channel roughness is usually highest at the first irrigation, we noted a lower roughness in the furrow for the initial run HEL-71 because the furrow was smoothed with an furrow shaped steel mould.

(4) Extensive field experiments were carried out over a 4-year period (1998-2001) on a loamy soil plot (44\% silt, $38 \%$ sand, $18 \%$ clay) under corn (variety Samasara) at the CEMAGREF experimental site Lavalette in Montpellier, France. Among standard measurements related to the surface flow (cut-throat flumes), the experimental site was equipped with soil moisture and matrix head sensors. Access tubes for measuring soil moisture with neutron probes were placed at the ridge and furrow bed of furrow No. 60 at furrow distance $x=20,65,110 m$ respectively. Measurements of meteorological data (Fig. 1), leaf-area index (LAI) and yield provided a complete set of furrow irrigation data for a whole growing season (cf. Mailhol 2001; Mailhol et al. 2001; Nemeth 2001). In 1999, About 30 closed-end furrows with an inter-furrow spacing of $f s=0.8 \mathrm{~m}$ were irrigated at the $130 \mathrm{~m}$ long $\mathrm{Ta}$-plot of Lavalette. The longitudinal furrow slope was $0.25 \%$ and the roughness coefficient was estimated to $K_{s t}=20 \mathrm{~m}^{1 / 3} \mathrm{~s}^{-1}$ for the first and $K_{s t}=25 \mathrm{~m}^{1 / 3} \mathrm{~s}^{-1}$ for the second and third irrigation respectively. Furrow cross sections were almost trapezoidal with a bottom width of $0.1 \mathrm{~m}$, a depth of $0.15 \mathrm{~m}$ and a top width of $0.4 \mathrm{~m}$. Corresponding hydraulic section parameters are listed in Table 1. 
The soil-profile of the Ta-plot is subdivided into three layers. Soil hydraulic characteristics (Table 2) were determined by direct and inverse methods (Mueller 2001). Corn was sown on May 26, 1999 and initially watered $(28 \mathrm{~mm})$ by a travelling gun system (sprinkler) in order to insure a homogeneous crop emergence. Due to over-average rainfall events (114 $\mathrm{mm}$ from June to the end of September), the plot was irrigated only three times: $76 \mathrm{~mm}$ at July 10, $67 \mathrm{~mm}$ at July 22, and $53 \mathrm{~mm}$ at August 25, 1999. Harvest started at October 11, 1999 (138 days after sowing) and average grain yield was 12.7t/ha at a grain moisture content of $15 \%$.

\section{Parameterization of the Lavalette Run}

FIM is designed for free-draining surface flow conditions (FDF) but the three irrigations at Lavalette were conducted by the closed-end-furrow method (CEF). However, we assume that the two upstream monitoring sections of the field (at the inlet location and at $x_{i n f}=32.5 \mathrm{~m}$ ) were not affected by backwater effects arising from the CEF practice for two reasons: Firstly, the inflow discharge was cut off shortly after the irrigation advance reached the downstream boundary of the field. The mean advance times were about three-quaters of the total irrigation duration and hence possible backwater effects on flow depth of the two upper sections occured only during a relatively small short time of the irrigation. Secondly, infiltration tests showed that the infiltration rate on the upstream part of the field had already declined significantly at the times when the advancing wave reached the field end. Hence possible differences in flow depth may not have a major impact on total infiltration volume at the upper field sections. In addition, backwater effects may be less pronounced at the upstream part of sloping furrows. With these assumptions, observed soil water content and crop growth data can be compared to results from FIM's FDF simulations at the two upstream monitoring sections. Five locations of infiltration computation were defined along furrow at $x_{i n f}=[0,32.5,65.0,97.5,130] \mathrm{m}$ respectively.

Observations of the initial soil moisture distribution at the day of sowing were not available. Measurements of volumetric water content started on June 21, 1999 (26 days after sowing) at the furrow ridges and only one month later (56 days after sowing) at the furrow beds. The measurements were taken at $x=[20,65,110 \mathrm{~m}]$ and a depth of $z=[-0.1,-0.2, \ldots-1.4 \mathrm{~m}]$ at irregular time intervals, varying between two days and two weeks. However, the soil moisture was measured at the site already on May 1, 1999, i.e. 26 days before sowing. At this date the average soil moisture was about $\theta_{w} \approx 0.2 \mathrm{~m}^{3} \mathrm{~m}^{-3}$ down to a depth of $1.2 \mathrm{~m}$. We initialized HYDRUS-2 with these data and conducted a forward simulation with the given meteorological boundary conditions to estimate the initial soil moisture distribution at the day of sowing. The simulated soil moisture content in the upper soil layer was slightly increased in order to match with the observed soil water storage on July 21, 1999. Fig. 2 shows the resulting soil moisture distribution for initialization of the Lavalette run. 
The atmospheric boundary conditions of the subsurface flow model HYDRUS-2 were calculated from the meteorological data (Fig. 1). About $70 \mathrm{~mm}$ water were applied between the time of sowing and mid of June by altogether four sprinkler irrigation events (Fig. 1). In FIM, the sprinkler irrigation events were treated mathematically like precipitation - as a flux across the soil-atmospheric boundary. The irrigation parameters of the three furrow irrigation events during the cropping season are listed in Table 1.

An initial FIM run with the soil parameterization given in Table 2 resulted in systematically too less infiltration. For example, the total simulated infiltrated volume of irrigation LAT-3 was simulated to $I_{\text {inf }}=34 \mathrm{~mm}$ $\left[10^{-3} \mathrm{~m}^{3} \mathrm{~m}^{-2}\right]$ at $x_{i n f}=32.5 \mathrm{~m}$, in comparison to the observed volume of $50 \mathrm{~mm}$. Due to the lack of a confirmed parameterization of the VGM model for the Lavalette soil, we slightly increased the values of the saturated hydraulic conductivity in the first soil layer to as $K_{s}=7.5 \cdot 10^{-6} \mathrm{~ms}^{-1}$ and of the second layer to as $K_{s}=1.85 \cdot 10^{-6} \mathrm{~ms}^{-1}$. These modifications resulted in a much better simulated infiltrated volume of $I_{\text {inf }}=51 \mathrm{~mm}$ (irrigation event LAT-3). Consequently, these modified hydraulic parameters were used for simulation of the Lavalette experiments.

The parameter for the crop growth and yield modules were found for corn as in Mailhol et al. 1997 and Mailhol 2001: the maximum value of the leaf area index $L A I_{\max }=4.5 \mathrm{~m}^{2} \mathrm{~m}^{-2} ; K_{c, \max }=1.2$; the plant density, desopt $=10$ plants per $m^{2}$, for which $L A I_{\text {max }^{-}}$values are given; the base temperature of the crop $T_{b}=6^{\circ} \mathrm{C}$; the thermal time of emergence $T_{s}=100^{\circ} \mathrm{C}$; the thermal time of maturity $T_{m a t}=1925^{\circ} \mathrm{C}$; the threshold thermal time, $T_{f}=1005^{\circ} \mathrm{C}$, corresponding to $L A I_{\max }$; the thermal times critical to crop development $T_{\text {crit } 1}=900^{\circ} \mathrm{C}, T_{\text {crit } 2}=1600^{\circ} \mathrm{C}$; the parameter governing the plant sensitivity to water stress $\lambda=1.25$; three parameters related to the slope of the $L A I$-curve, $\beta=2.4, \delta_{1}=14, \delta_{2}=0.2$; the harvest index $H I=0.52$; and the radiation use efficiency $R U E=1.32 \mathrm{gMJ}^{-1}$. The root growth parameters and the related HYDRUS-2 parameters were: initial root depth $z_{r, \text { init }}=0.1 \mathrm{~m}$; maximum root depth $z_{r, \max }=1.2 \mathrm{~m}$; time when maximum root depth is reached $t_{r d}=72$ days; critical soil surface pressure head $h_{\text {crit }}=-160 \mathrm{~m}$; and the parameters of the water stress response function by Feddes et al. (1978) $h_{a}=-0.15 m, h_{d 1}=-3.0 m$, $h_{d 2}=-35.0 m, h_{o p t}=-0.3 m, h_{w p}=-130.0 m, T P\left(h_{d 1}\right)=6 e^{-8} m s^{-1}, T P\left(h_{d 2}\right)=1.6 e^{-8} m s^{-1}$.

\section{Evaluation Criteria}

In order to evaluate how well does the coupled model fit to the measured irrigation advance and recession data, five statistical parameters are used in this study, which are the root-mean-square error, $R M S E$, the coefficient of determination, $R^{2}$, and the coefficient of efficiency by Nash-Sutcliffe (ASCE 1993)

$$
C_{e}=1-\frac{\sum_{i=1}^{N}\left(t_{o}^{(i)}-t_{p}^{(i)}\right)^{2}}{\sum_{i=1}^{N}\left(t_{o}^{(i)}-\bar{t}_{o}\right)^{2}} .
$$


where $t_{p}$ and $t_{o}$ denote the predicted and observed advance or recession times respectively, and $N$ is the number of data points used in the evaluation. $C_{e}$ is a widely used fitting criterion and an analogy to the coefficient of determination familiar from the analysis of variance. It may assume negative numbers if the mean square error exceeds the variance of the observations (Hall 2001). Model predictions are considered satisfactorily if the values of $R^{2}$ and $C_{e}$ assume similar values close to unity.

In contrast to the above criteria, the sensitivity index, $S I$, is used in this study to determine the sensitivity of predicted advance times and runoff to the various input parameters. It can be defined as the rate of change in the output value resulting from a change of this input parameter while keeping all other parameters constant. The sensitivity index, $S I$ in [\%], as proposed by $\mathrm{Ng}$ and Loomis (1984) is calculated to as

$$
S I=\frac{\frac{100}{N} \cdot \sum_{i=1}^{N} \frac{\left(X_{n i}-X_{c i}\right)}{X_{c i}}}{\Delta}
$$

where, $X_{n i}=$ the new value of the $i^{t h}$ data point with a changed value of the input parameter; $X_{c i}=$ the value of output for the $i^{\text {th }}$ point in the control simulation run and $\Delta=$ the change in the input parameter, expressed as a percentage of its value in the control simulation respectively. The $S I$ is a measure of the percentage change in the output of the control run resulting from a one percent change in the input parameter value.

\section{Results}

\section{Coupled Surface-Subsurface Flow}

Advance and recession phase modeling is numerically much more challenging as compared to modeling of the other surface flow phases in furrow irrigation. FIM's advance phase model performs satisfactory for data from field-scale laboratory experiments, data from Kharagpur and the Flowell-Wheel data as shown in Wöhling et al. (2006). In this study we also predicted recession times for these runs. The calculated recession times of the KGP-5 run are in agreement with the observations which is confirmed by $R M S E, R^{2}$ and $C_{e}$ values of $1.2 \mathrm{~min}, 1.00$ and 0.74 respectively (cf. Table 4). Even the first run, where soil was freshly prepared and therefore not yet stable in structure, shows an good match between the observed and simulated advances, which is confirmed by $R M S E, R^{2}$ and $C_{e}$ values of $2.3 \mathrm{~min}, 0.99$ and 0.7 respectively. Performance indices are poor for the KGP-1 recession times. However, the RMSE is relatively small at $1.7 \mathrm{~min}$. Recession was observed at only four locations. Two data points out of the four are poorly predicted by FIM which results in small coefficients of efficiency and determination. Nevertheless, this must not be overrated for the following reasons: Physically, one would not expect a slow recession within the first quarter of the field length preceding a comparative fast recession at the remaining three quarters of the field as the observations 
indicate (Fig. 4). Moreover, difficulties to measure field data - recession times in particular - are frequently reported in literature (e.g. Esfandiari and Maheshwari 2001).

We tested FIM for five of the Hubert-Engels-Laboratory runs. HEL-7 and HEL-9 were runs with two consecutive irrigations, i.e HEL-71, HEL-72, HEL-91, and HEL-92. The model simulated both irrigations in a single run. It was initialized for HEL-71, simulated HEL-71, then the redistribution time between the two irrigations, and subsequently HEL-72. Thus, the initial conditions of HEL-72 were predicted by the model. The same procedure was followed for HEL-91 and HEL-92. FIM performed very well in predicting the advance times of all experiments as seen in Table 4. The coefficients of determination and efficiency are $R^{2} \geq 0.99$ and $C_{e} \geq 0.79$ respectively. Predicted recession times also agree with the observations, but the coefficients of determination and efficiency are lower at $R^{2} \geq 0.89$ and $C_{e} \geq 0.58$. In accordance, the $R M S E$ values are generally higher for predicted recession times as compared to predicted advance times (Table 4). This is partly due to the well-known difficulty to observe recession times. Even the observed recession times under laboratory conditions were not always increasing with furrow length as we might expect (Fig. 3).

However, the KGP and HEL experiments were limited to relatively short furrows ( $\leq 40.0 \mathrm{~m}$ field length). Irrigation projects in Southern France or in the US, on the other hand, have often furrow lengths from over $100 \mathrm{~m}$ and can reach uo to $1000 \mathrm{~m}$. Irrigation control with respect to a uniform water application is much more challenging in relatively long furrows as compared to shorter furrows due to the advance process. FIM's ability to accurately predict advance times in a $360 \mathrm{~m}$ long furrow of the "Flowell wheel" run (Walker and Humpherys 1983) was reported in Wöhling et al. (2006). Predicted advance times match very well with the observations which was confirmed by $R M S E, R^{2}$ and $C_{e}$ values of $9.5 \mathrm{~min}, 0.99$ and 0.99 respectively (Table 4). FIM tend to over predict recession times toward the end of the field which was confirmed by a poor coefficient of efficiency (Table 4) However, the average absolute error was only $1.9 \%$ of the total irrigation time and the coefficient of determination was 0.98 .

The 138 days growing season at Lavalette experiments including the three irrigation events was simulated by a single FIM run. Due to the assumptions made in the parameterization section and the set up of the experiments (CEF irrigation technique), we can analyse the simulated advance times but not the recession times. FIM predicts a much faster advance as against observed, which is reflected by poor performance indices of $R M S E>17 \mathrm{~min}$ and $C_{e}<0.52$. Althoght $R^{2}$ values are high $\left(R^{2}>0.99\right)$, the low values of the coefficients of efficiency indicate a strong bias of the model results. However, the overall volume of infiltration during the three experiments match with the observations. How is this possible, when the advance times do not match? We investigated the problem with a rough estimate of the physical maximum of infiltration for the given parameterization of the soil: At the time, when the irrigation advance has just reached the 
downstream field boundary, the volume balance can be roughly estimated to as

$$
Q_{0} \cdot t_{s}-\bar{A} \cdot x_{L}=\overline{w p} \cdot x_{L} \cdot K_{S} \cdot t_{s}
$$

where $Q_{0}$ denotes the constant inflow rate, $t_{s}$ is the advance time at the downstream field boundary $\left(x_{L}\right)$, $\bar{A}$ is the mean cross sectional area, $\overline{w p}$ is the corresponding mean wetted perimeter and $K_{s}$ is the saturated conductivity of the first soil layer. The first and second term on the left hand side of Eq. (3) denotes the inflow volume and the volume of water in the furrow respectively, assuming a horizontal (mean) water level $\bar{h}_{w l}$. The right hand side of Eq. (3) is an estimate of the maximum possible infiltration volume assuming the total field length flooded from the begin of the water application (thus neglecting the advance process and overestimating infiltration opportunity time and infiltration volume at the lower part of the field). In case of irrigation LAT-3, the mean observed flow depth was $0.05 \mathrm{~m}$ and thus $\bar{A}$ and $\overline{w p}$ is calculated to $7.44 \cdot E^{-3} \mathrm{~m}^{2}$ and $0.249 \mathrm{~m}$ respectively. Solving Eq. (3) using these values and $K_{s}=7.7 \cdot E^{-7} \mathrm{~m} / \mathrm{s}, x_{L}=130 \mathrm{~m}$ and $t_{s}=4740 s$ (mean) leads to:

$$
3.65-0.97>1.17
$$

According to this rough estimation, the infiltrated volume (inflow volume minus volume in the furrow) must be about $2.68 \mathrm{~m}^{3}$ at the time $t=t_{s}$. But the physical maximum of infiltration for the given parameterization is less than $1.17 \mathrm{~m}^{3}$. Therefore, the initial water flux into the soil (i.e. shortly after wetting) is higher as the given $K_{s}$-value. It can be concluded that the parameterization of the soil model does not represent the dynamics of soil water movement of the Lavalette experiments. The simulated infiltration rates are too low for short irrigation times; too high for long infiltration times.

\section{Parameter sensitivity}

A sensitivity analysis was conducted to analyze which input parameters have the most significant effect on the model output. The control runs for the sensitivity analysis are HEL-71 and FW, representing a short and a long furrow respectively. Thirteen input parameters are included in the study: the longitudinal slope, $S_{0}$, the furrow geometry parameters, $p_{1} . . p_{4}$, the roughness coefficient, $K_{s t}$, the inflow rate, $Q_{0}$, the VGM model parameters $\theta_{r}, \theta_{s}, \alpha, n$ and $K_{s}$, and the initial matrix head, $h_{m}$. The sensitivity of these input parameters is analyzed with respect to advance time (controling uniformity of the water application) and runoff (controling the efficiency of the water application). All parameters were changed by $-50 \%$ and $+50 \%$ in accordance with the approach of Esfandiari (1997). Each of the VGM parameters were changed simultaneously in all soil layers rather than independently for each layer.

The $S I$-values for the HEL-71 run range between $+1.69 \% /-0.94 \%$ and $1.47 \% /-1.40 \%$ for advance times 
and runoff respectively. Most sensitive to advance times is a furrow geometry parameter: one percent increase in $p_{4}$ results in a $1.69 \%$ increase in calculated advance time. This reflects that, in contrast to empirical infiltration formulas, HYDRUS-2 infiltration (as in FIM) depends on flow depth and geometry factors (wetted perimeter). An increase in $Q_{0}$ leads to an almost proportional increase in calculated advance time $(S I=+0.94 \%)$, whereas a change in $\theta_{r}, \alpha$ or initial soil moisture $h_{m}$ has almost no effect on advance times $(S< \pm 0.07 \%)$. The low sensitivity of $h_{m}$ is caused by the fact, that the change in soil moisture resulting from the change of $h_{m} \pm 50 \%$ is only few percent. For the short furrow of HEL-71, longitudinal slope and soil hydraulic parameters are not very sensitive to advance time $(S I< \pm 0.29 \%)$. With respect to runoff, the inflow rate, $Q_{0}$, is the most sensitive input parameter of the HEL-71 run which is confirmed by $S I$-values of $+1.47 \% /-1.40 \%$. Rank three and four are taken by the exponents $p_{2}$ and $p_{4}(S I=-0.58 / 0.54 \%)$ which govern the geometry functions $h(A)$ and $R(A)$. Changes in initial soil moisture $h_{m}$ and $\theta_{r}$ again have a negligible effect on calculated runoff.

The $S I$-values for the FW run range from $+3.56 \%$ to $-0.82 \%$ and +9.06 to $-0.45 \%$ for advance and runoff, respectively. Most sensitive to advance times are $-Q_{0},-p_{2},+n,-\alpha,+p_{4}$, and $+K_{s}$ with $S I$ - values well above 1\%. The infiltration parameters $K_{s}, n$ and $\alpha$ are more sensitive to advance in the long furrow as compared to the short furrow of the HEL-71 experiment. The roughness coefficient, $K_{s t}$, has a similar $S I$-value for both the long and the short furrows $(S I=1.02 \%$ and $0.94 \%$ respectively). The field slope, the saturated soil moisture content, the residual soil moisture content, and initial matrix head range again among the least sensitive input parameters for the FW run. The inflow rate $Q_{0}$ is most sensitive with respect to calculated runoff $(S I=+9.06 \%)$ followed in decreasing order of sensitivity by $K_{s}(S I=+7.96 \%), p_{2}(S I=+4.89 \%), p_{1}$ $(S I=+4.33 \%)$, and $\alpha(S I=+1.82 \%) . S I$-values are generally much higher for the Flowell run as compared to the HEL-71 run, which is probably a consequence of the nine times longer furrow and the about four times higher irrigation time.

\section{Simulation of a Growing Season}

FIM was tested on data of the whole growing season of the 1999 Lavalette experiments. FIM was initialized and parameterized using the data described above. It simulated the 138 days of the corn cropping cycle in one run. The run required about 9 minutes $\mathrm{CPU}$ time on a $\mathrm{PC}$ with a Pentium M755/2.0 GHz processor and 0.5GB RAM; and 5.7 minutes on the same computer when we consider a symmetrical furrow and cut the HYDRUS-2 flow domain vertically by half. 


\section{Volume Balance}

Altogether $59.0 \mathrm{~m}^{3}$ water were consumed by crop evapotranspiration during the corn cropping season. This water was provided mainly by rainfall events $(56 \%)$, by irrigation $(27 \%)$, and by the water which was stored in the soil (17\%). The total volume of irrigation water was $20.7 \mathrm{~m}^{3}$. A share of $16.1 \mathrm{~m}^{3}(88 \%)$ of this water infiltrated into the soil and $4.5 \mathrm{~m}^{3}(22 \%)$ left the field by surface runoff. The loss due to percolation in deeper soil layers was relatively low at $0.6 \mathrm{~m}^{3}$. The field inlet and the section $x_{i n f}=32.5 \mathrm{~m}$ can be considered untainted with the backwater effects of the CEF irrigation practice. Both the total actual transpiration and the total actual evaporation at these sections were close to its potential values $(T P=345 / 343 \mathrm{~mm}$; $E P=274 / 275)$ which indicates that the plants were supplied sufficiently with water during the whole growing period. Fig. 6 presents the simulated soil water storage, $S_{\text {soil }, s}$, (water volume stored in a soil column of certain depth) in the full grown root zone $(0.0-1.2 \mathrm{~m}$ depth $)$ at $x_{i n f}=32.5 \mathrm{~m}$ in comparison to the measured soil water storage, $S_{\text {soil }, m}$ in the same zone at $x=20 \mathrm{~m}$. $S_{\text {soil }, \mathrm{s}^{-}}$values agree very well with the first field observations $\left(59^{\text {th }}, 61^{\text {th }}\right.$ and $65^{\text {th }}$ day after sowing). This agreement is also a confirmation of the simulated initial soil moisture distribution. The simulated increase of the storage due to both rainfall events and irrigation events $\left(45^{\text {th }}, 57^{\text {th }}\right.$ and $91^{\text {th }}$ day after sowing) also compared favourably with the observations. Similarly, long drying periods $\left(73^{\text {th }}-90^{\text {th }}\right.$ day and $112^{\text {th }}-138^{\text {th }}$ day) were correctly simulated.

\section{Soil Moisture Profiles}

Volumetric soil moisture content, $\theta_{w}$, was measured at various depths, $z_{l}$. The function $\theta_{w}=f\left(z_{l}\right)$ is referred to as soil moisture profile. In order to make the FIM simulations comparable to the observations, soil moisture profiles were calculated by horizontal discretization of the subsurface flow domain according to the $z_{l}$-values and by averaging $\theta_{w}$ within the resulting depth layers.

Fig. 7 shows simulated and observed soil moisture profiles (at $x=20 \mathrm{~m}$ and $x_{\text {inf }}=32.5 \mathrm{~m}$ ) at times before and after the irrigation events and at five days before harvest. Simulated soil moisture profiles compare favourably with the observations at the days before the irrigations (at 45, 57, and 90 days after sowing). The observed moisture content showed a maximum at $z=0.2 \mathrm{~m}$ immediately after the irrigations LAT-2 and LAT-3, whereas the simulated moisture in the upper $0.5 \mathrm{~m}$ soil depth was almost uniform. The latter was due to the fact, that HYDRUS-2 simulates the diffusive effect (matrix flow) and does not account for possible preferential flow paths which may have existed in the field due to organic matter, remaining root channels, animal activity or soil cracking.

There was generally a good agreement between the observed and simulated moisture of the deeper soil layers. The observed moisture profile on the $133^{\text {th }}$ day after sowing, however, differed from the simulated moisture which is steadily increasing with soil depth as shown in Fig. $7 d)$. In the upper soil layer $(0.0 \ldots 0.6 \mathrm{~m})$, the 
observed moisture content was higher as the simulated whereas it was lower in the next layer $(0.6 . .1 .2 \mathrm{~m})$. These differences were almost counterbalancing in the integral water storage as seen in Fig. 6 .

2D contour plots of simulated soil moisture at $x_{i n f}=32.5$ are presented in Fig. 8 for selected times. Fig. 8a) shows a distinct moisture gradient at the soil surface due to a recent rainfall event $(13.5 \mathrm{~mm})$ and soil evaporation. After long drying periods without precipitation, the volumetric water content was horizontally uniform and increased with the soil depth as seen in Fig. 8d). This was a consequence of the redistribution process but also of the assumption of uniform root distribution in the soil. The horizontal uniformity of $\theta_{w}$ below the root zone was present during the whole growing season. The moisture distribution before the $3^{\text {rd }}$ irrigation (Fig. 8b)) resulted from the relatively high water extraction rate by plant roots (at $0.0 . .1 .0 \mathrm{~m}$ depths, 90 days after sowing). There was a high moisture gradient from deeper soil layers - where the water content was significantly higher - toward the lower boundary of the root zone. Only about 15 hours after irrigation, the simulated wetting front had advanced to a depth of $0.5 \mathrm{~m}$ (Fig. 8c)).

\section{Evapotranspiration}

Fig. 9 shows the simulated components of evapotranspiration, namely soil evaporation and transpiration, at $x_{i n f}=32.5 \mathrm{~m}$ for the growing season. The predicted actual crop transpiration, $T A$, was always close to its potential values, TP. Transpiration was increasing with crop growth while soil evaporation was decreasing because of the shading of the leafs (leaf area index, $L A I$, increases). After crop maturity, the soil evaporation increased again because the leaves of the corn started drying up (and consequently $L A I$-values decreased). The soil evaporation was at the potential rates at times between the $50^{\text {th }}$ day after sowing and harvest. $E A$ reached its characteristic minimum, when the $L A I$ was at its maximum (at the $72^{\text {th }}$ day after sowing).

\section{Leaf Area Index}

Fig. 10 shows the $L A I$ observations (together with it's standard deviation) and the functions of both the actual simulated leaf area index, $L A I$, and the potential simulated leaf area index, $L A I_{\text {pot }}$, at the cross section $x_{i n f}=32.5 \mathrm{~m}$. The potential leaf area index was calculated by FIM assuming optimal growth conditions, i.e. no plant water stress. The simulated $L A I$ matched very well the observations during the early growing stage until 56 days after sowing. Later in the season, it was higher than the observed values and reached its maximum on the $72^{\text {th }}$ day after sowing. After that, simulated $L A I$-values were declining, whereas the observations showed values of around $4.5\left[\mathrm{~m}^{3} \mathrm{~m}^{-3}\right]$ on the $87^{\text {th }}$ and the $99^{\text {th }}$ day after sowing (Fig. 10). These values were close to the maximum $L A I$ value for the corn variety under consideration. The observed $L A I$ values indicated better growing conditions during the late maturity stage than during early maturity and as a response - an increasing $L A I$. But the observed soil water storage during late maturity was less than 
the storage during early maturity (Fig. 6) which does not support the above hypothesis. The measurements of $L A I$ were not easy to perform and may be afflicted with large errors.

\section{Yield}

The potential grain yield was calculated to $Y_{m}=12.0 t$ corn $h a^{-1}$ by Eq. (33) in Wöhling and Schmitz (2006) with the harvest index, $H I=0.5$, and the radiation use coefficient, $R U E=1.32 g \cdot M J^{-1}$. Eq. (36) in Wöhling and Schmitz (2006) was used for calculation of the actual grain yield $Y_{a}=11.1$ tha $a^{-1}$ Taking into account that both equations are given for dry grain yield (i.e. a corn moisture content of $0 \%$ ), we finally obtain an average grain yield of $12.8 \mathrm{tha}^{-1}$ at a grain moisture content of $15 \%$. This value matches very well with the observed average grain yield of $12.7 \mathrm{th \textrm {a } ^ { - 1 }}$.

The ability of correctly predict corn yield by the PILOTE model - whose crop module algorithm is utilized in FIM - was already reported in Mailhol et al. (1997); Mailhol and Ruelle (1999); Mailhol (2001). Therefore we like to refer to these earlier studies for parameter sensitivity and further model performance information.

\section{Conclusions}

In this contribution, FIM, a physically based furrow irrigation model was tested and validated. We used data from five real-scale laboratory experiments and data from field experiments at three different sites. Model simulations are in good agreement with observed advance and recession times for both the long furrow of the Flowell-Wheel run (FW), and the short furrow of the laboratory experiments (HEL) as well as the field experiments in Kharagpur (KGP). Advance times are generally more accurately predicted as recession times. This is partly due to the often difficult measurement of recession times and partly due to the simplified description of surface flow during the recession phase (as described in Wöhling and Schmitz 2006). A sensitivity analysis revealed that a furrow geometry parameter was most sensitive to calculated advance times in a short furrow with low infiltration opportunity time, whereas the inflow rate and infiltration parameters were more sensitive to calculated advance times in the long furrow with larger infiltration opportunity time. For both the short furrow and the long furrow the inflow rate was more sensitive to calculated advance times and runoff as compared to infiltration parameters. But an inappropriate estimation of the soil hydraulic parameters and/or macro-pore effects present in the field can easily lead to rather large errors in predicted advance times as seen in the case of the Lavalette experiments in France. Although the simulated total infiltration volume of the irrigation events match with the observations, the dynamics of water movement during the initial wetting of the soil are not correctly mapped. This has but little effect on the simulation of the soil moisture storage at an upstream section of the 1999 Lavalette experiments, which match well with 
the soil moisture storage calculated from neutron probe measurements. The calculated soil moisture profiles also match well with the observed ones as confirmed at several times during the growing season. Simulated daily values of potential/actual evaporation and transpiration confirmed that the corn crop was under nearoptimum growth conditions during the whole growing season. Therefore, the calculated leaf-area index is also close to its potential values. It showed some deviations to the observed leaf-area index during maturity, but otherwise compared favorably. Altogether, predicted grain yield tallies very well with the observations. Further experimental data is required to test FIM under different soil conditions and cropping schemes. However, the model performed satisfactorily on the data under investigation. FIM is quite flexible to be adapted for many specific tasks. The present study shows its potential to improve irrigation design and water management at the scale of a cropping season with modern process-based modeling approaches. 


\section{References}

Alvarez, J. (2003). Estimation of advance and infiltration equation in furrow irrigation for untested discharges. Agric. Water Manag., 60:227-239.

ASCE (1993). Task committee on definition of watershed models of the watershed management committee, Irrigation and drainage division.: Criteria for evaluation of watershed models. J. Irrig. Drain. Div., 119(3):429-442.

Esfandiari, M. (1997). Evaluation of Furrow Irrigation Models for South-East Australia. PhD thesis, School of Agricultural and Rural Developement, University of Western Sydney-Hawkesbury, Richmond, NSW Australia.

Esfandiari, M. and Maheshwari, B. L. (2001). Field evaluation of furrow irrigation models. J. agric. Engng. Res., 79(4):459-479.

Feddes, R. A., Kowalik, P., and Zaradny, H. (1978). Simulation of field water use and crop yield. John Wiley and Sons.

Hall, J. M. (2001). How well does your model fit the data? Journal of Hydroinformatics, 3:49-55.

Haverkamp, R., Kutilek, M., Parlange, Y.-J., Rendon, L., and Krejca, M. (1988). Infiltration under ponded conditions: 2.Infiltration equation tested for parameter time-dependence and predictive use. Soil Science, $145: 317-329$

Mailhol, J. and Gonzalez, J. (1993). Furrow irrigation model for real-time application on cracking soils. $J$. Irrig. Drain. Eng., 119(5):768-783.

Mailhol, J., Priol, M., and Benali, M. (1999). A furrow irrigation model to improve furrow irrigation practices in the gharb valley of morocco. Agric. Water Manag., 42:65-80.

Mailhol, J. and Ruelle, P. (1999). Un outil operationnel pour l'analyse des strategies d'irrigation du mais au moyen d'un canon enrouleur. In ICID 17th international congress, Grenada, 11-19 Sept. 1999.

Mailhol, J. C. (2001). Contribution a l'amelioration des pratiques d'irrigation a la raie par une modelisation simplidiee a l'echelle de la parcelle et de la saison (in French. PhD Thesis.

Mailhol, J. C., Olufayo, A. A., and Ruelle, P. (1997). Sorghum and sunflower evapotranspiration and yield from simulated leaf area index. Agricultural Water Management, 35:167-182.

Mailhol, J. C., Ruelle, P., and Nemeth, I. (2001). Impact of fertilisation practices on nitrogen leaching under irrigation. Irr. Sci., 20:139-147. 
Mueller, A. (2001). Estimation of hydraulic soil parameters of tilled soil using direct and inverse methods.

CEMAGREF, Serie Irrigation, Departement Equipements pour l'Eau et l'Environnement, 361, rue JeanFrancois Breton, BP 5095, 34033 Montpellier Cedex 01.

Nemeth, I. (2001). Devenir de l'azote sous irrigation gravitaire. Application au cas d'un perimetre irrigue au mexique. (in French). PhD thesis, University of Montpellier II.

Ng, E. and Loomis, R. S. (1984). Simulation of growth and yield for the potato crop. Simulation monographs., Wageningen, the Netherlands: Pudoc.

Oyonarte, N., Mateos, L., and Palomo, M. (2002). Infiltration variability in furrow irrigation. J. Irrig. Drain. Eng., 128(26):26-33.

Peroux, K. and White, I. (1988). Design for disc permeameter. Soil Sci. Soc. Am. J., 52:1205-1215.

Schaap, M. and Leij, F. (1998). Using neuronal networks to predict soil water retention and soil hydraulic conductivity. Soil Tillage Res., 47:37-42.

Schmitz, G., Schütze, N., and Wöhling, Th. (2006). Irrigation control: towards a new solution of an old problem. IHP, International Hydrologic Programme, Stuttgart (Germany), (in Print).

Vachaud, G., Dancette, C., Sonko, L., and Thony, J. (1978). Methodes de caracterisation hydrodynamiques in situ d'un sol non sature. application a deux types de sol du senegal en vue de la determination des termes du bilan hydrique. (in french). Soil Sci. Soc. Am. J., 44:892-898.

Walker, W. R. and Humpherys, A. S. (1983). Kinematic-wave furrow irrigation model. Journal of Irrigation and Drainage Engineering, 109(4):377-392.

Wöhling, Th., Fröhner, A., Schmitz, G. H., and Liedl, R. (2006). Efficient solution of the coupled 1d surface - 2d subsurface flow during furrow irrigation advance. Journal of Irrigation and Drainage Division, 132(4).

Wöhling, Th. and Schmitz, G. (2006). A physically based coupled model for simulating 1d surface - 2d subsurface flow and plant water uptake in irrigation furrows. I: Model development. submitted to the Journal of Irrigation and Drainage Eng.

Wöhling, Th., Singh, R., and Schmitz, G. H. (2004). Physically based modeling of interactive surfacesubsurface flow during furrow irrigation advance. Journal of Irrigation and Drainage Division, 130(5):349356. 


\section{Acknowledgements}

The autors would like to thank the German Research Foundation (DFG), who kindly sponsored this project over a period of six years at the Dresden University of Technology, Germany. 

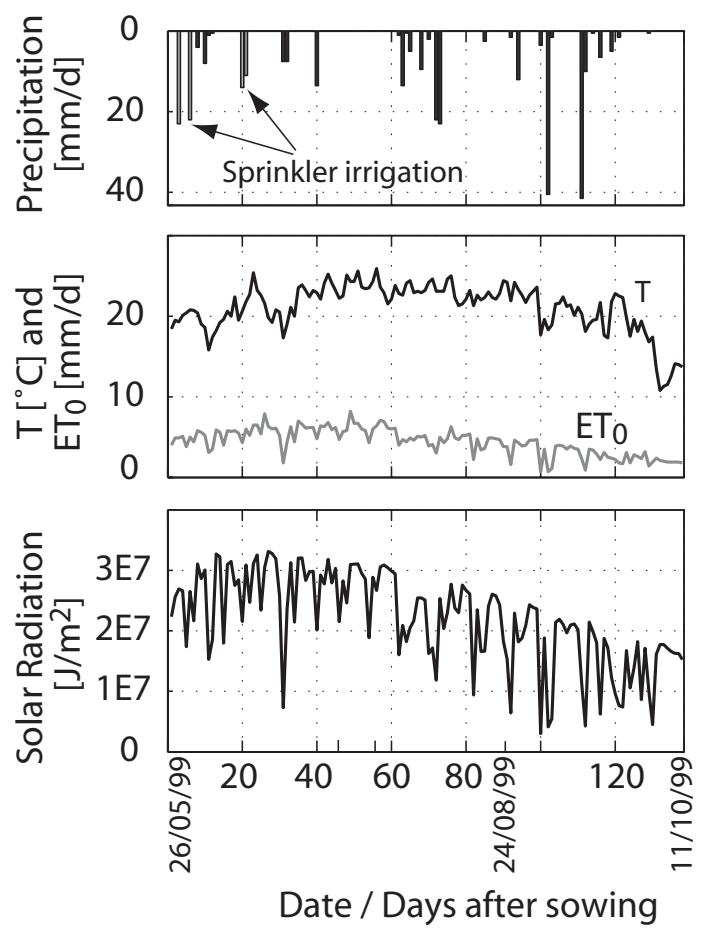

Figure 1: Meteorological data observed at the Ta-plot of the Lavalette site (1999) 


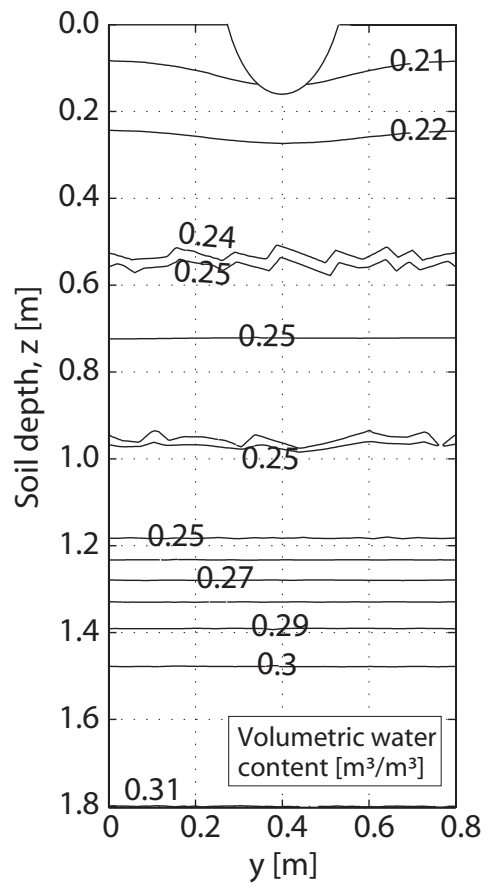

Figure 2: Initial soil moisture distribution, as simulated for the day of sowing of the Lavalette run 

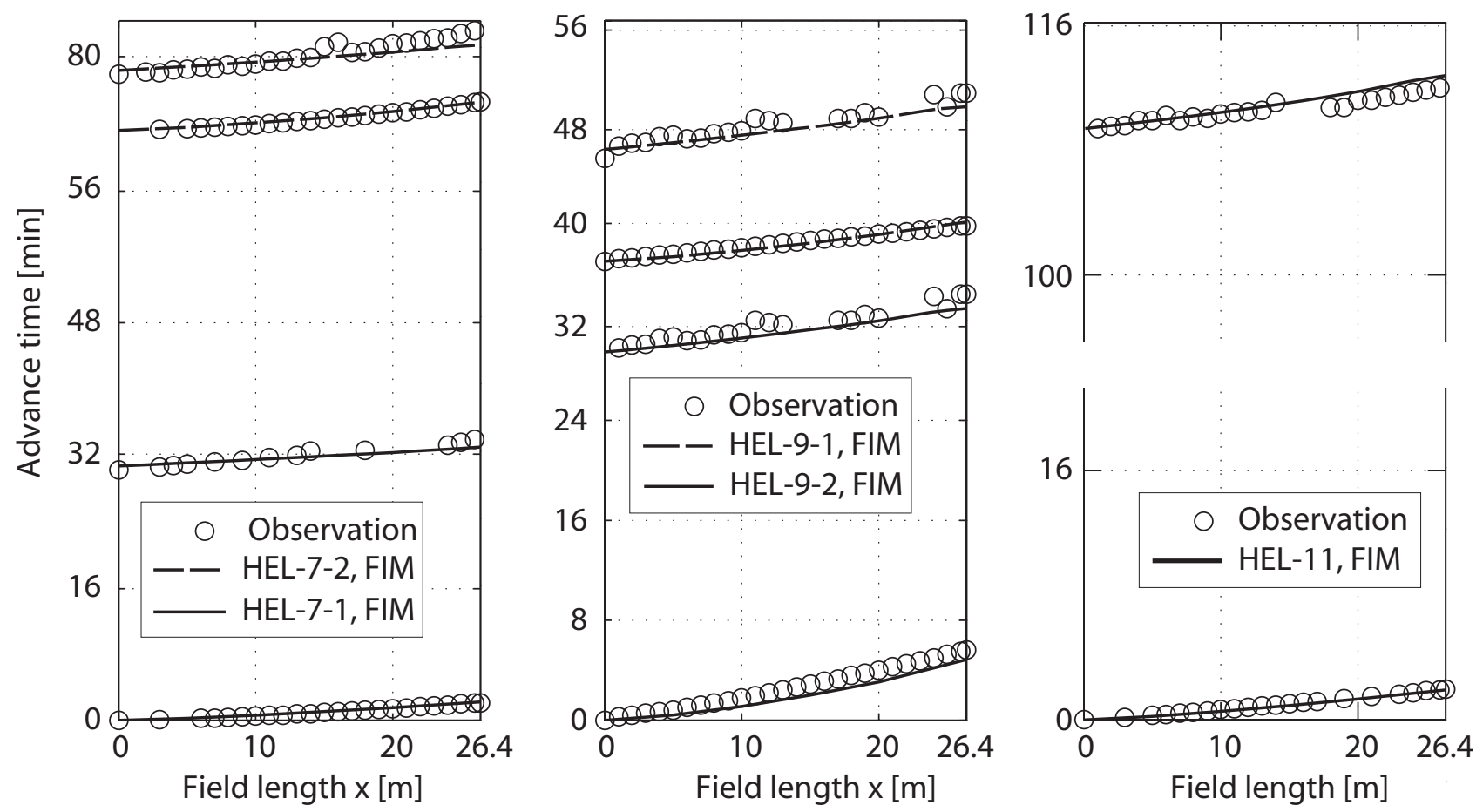

Figure 3: Observed and simulated advance and recession times for the HEL runs 

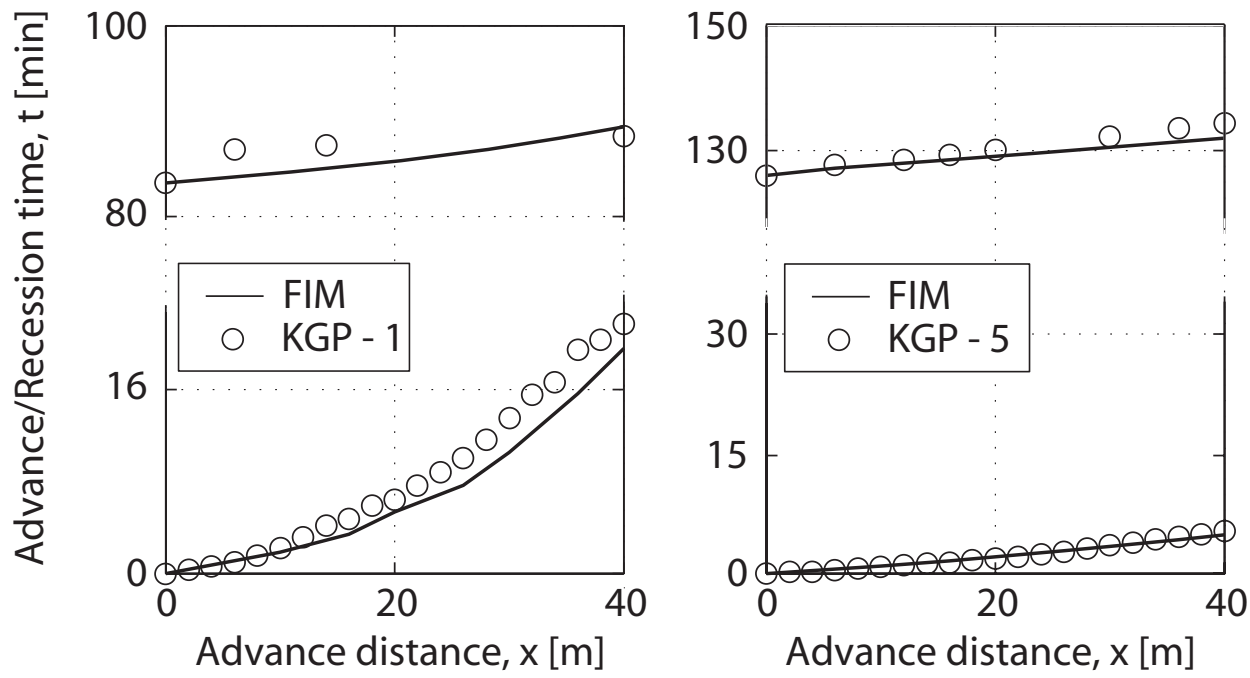

Figure 4: Observed and simulated advance and recession times for the KGP runs 


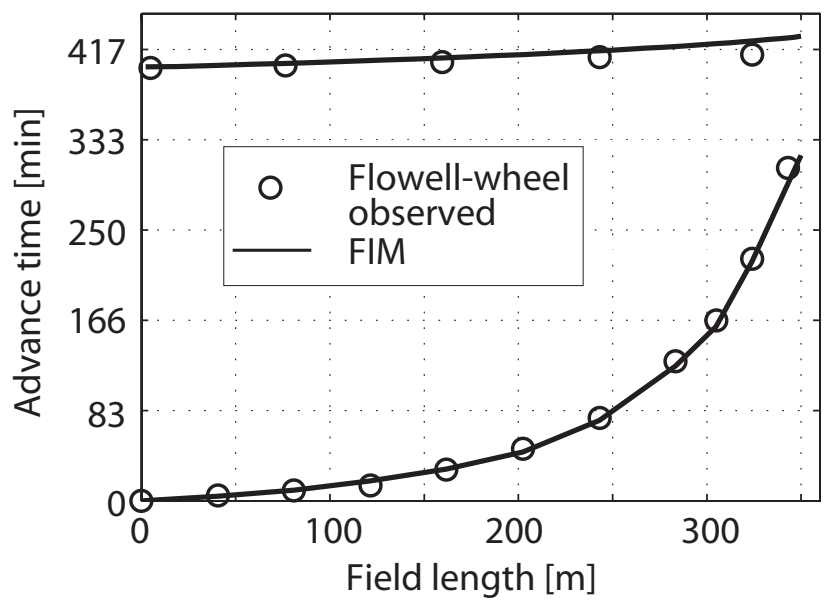

Figure 5: Observed and simulated advance and recession times for the Flowell-wheel run 


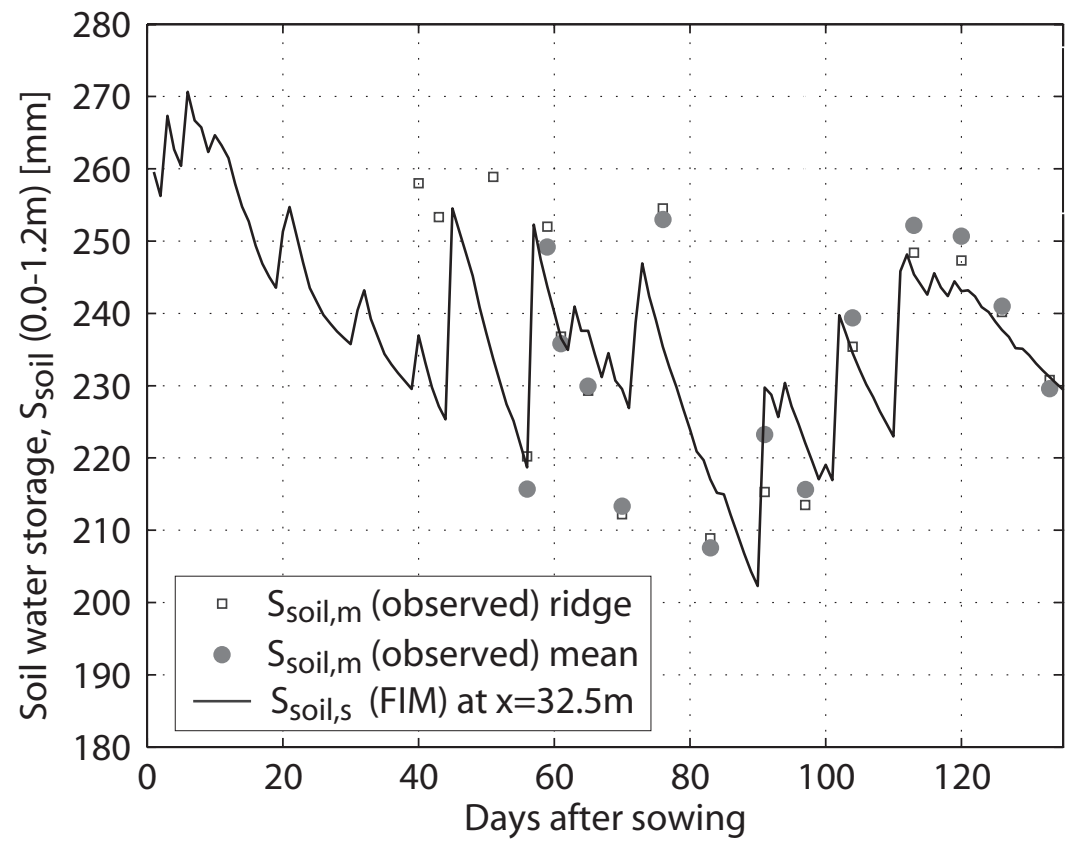

Figure 6: Observed and simulated soil water storage at the upstream section, $x_{i n f}=32.5 \mathrm{~m}$, during the entire 1999 growing season of corn at Lavalette 
a) Irrigation LAT-1

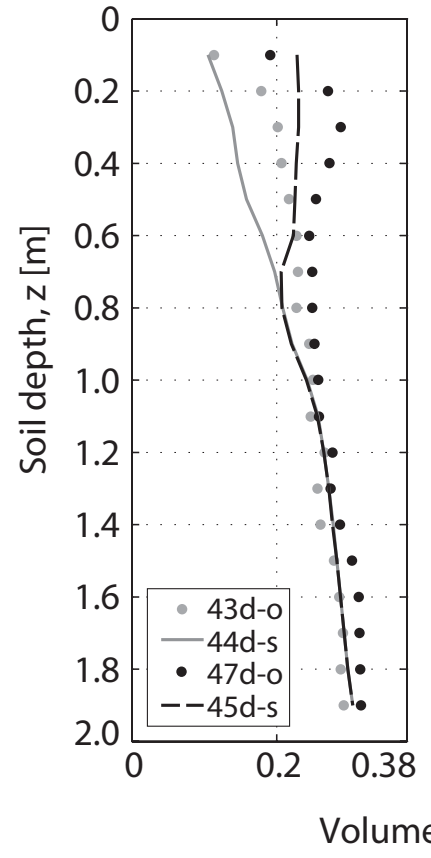

b) Irrigation LAT-2

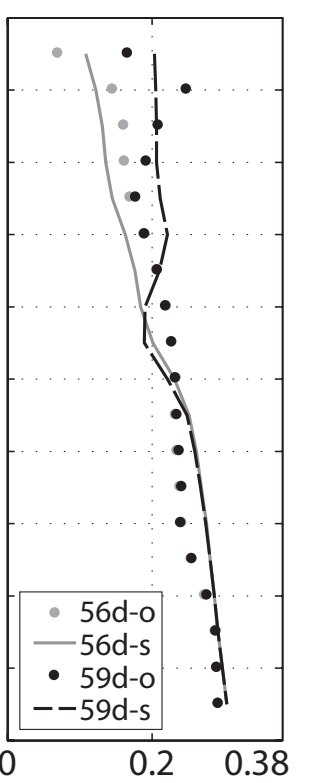

c) Irrigation LAT-3

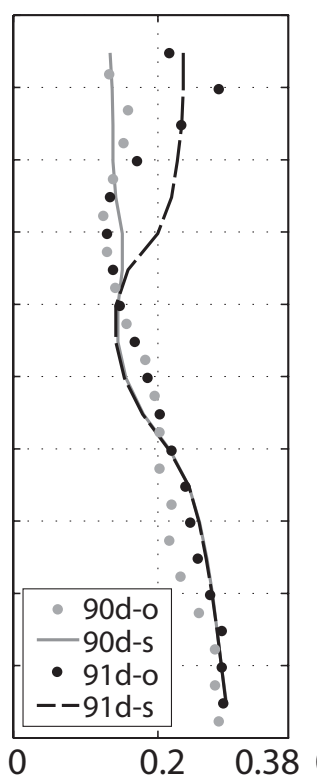

d) Near Harvest

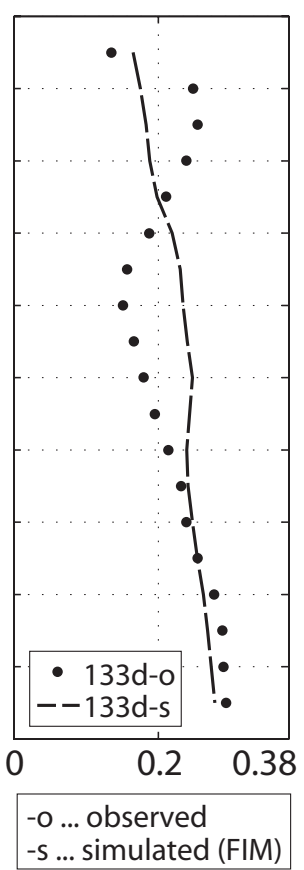

Figure 7: Simulated and observed soil moisture profiles at $x=20 \mathrm{~m} / x_{\text {inf }}=32.5 \mathrm{~m}$ for various times of the 1999 growing season at Lavalette 


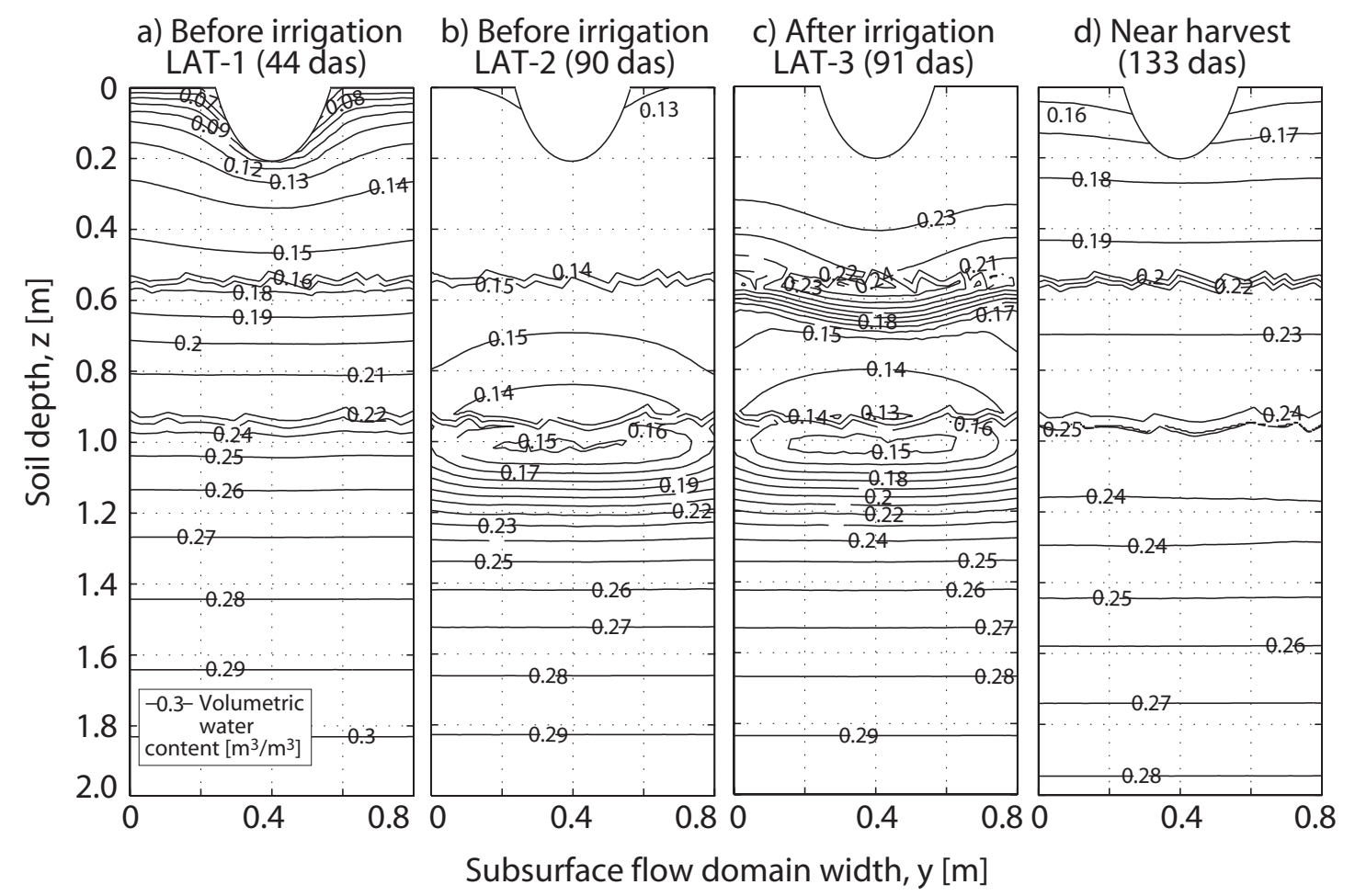

Figure 8: Simulated soil moisture distribution at $x_{i n f}=32.5 \mathrm{~m}$ for various times of the 1999 growing season at Lavalette 


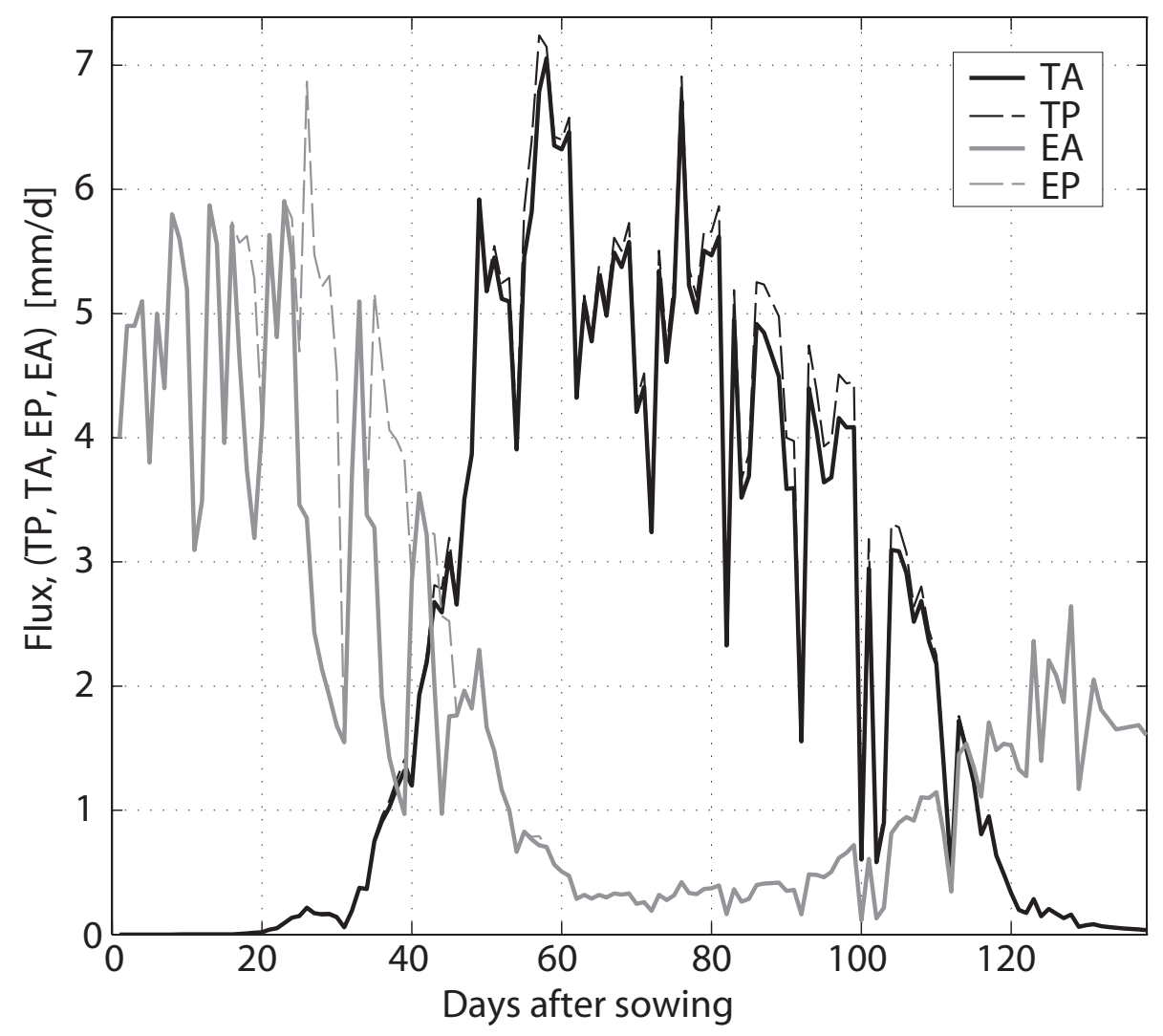

Figure 9: Simulated components of evapotranspiration at $x_{i n f}=32.5 \mathrm{~m}$ during the entire growing season of the Lavalette run: potential transpiration $T P$, actual transpiration $T A$, potential evaporation $E P$ and actual evaporation $E A$ 


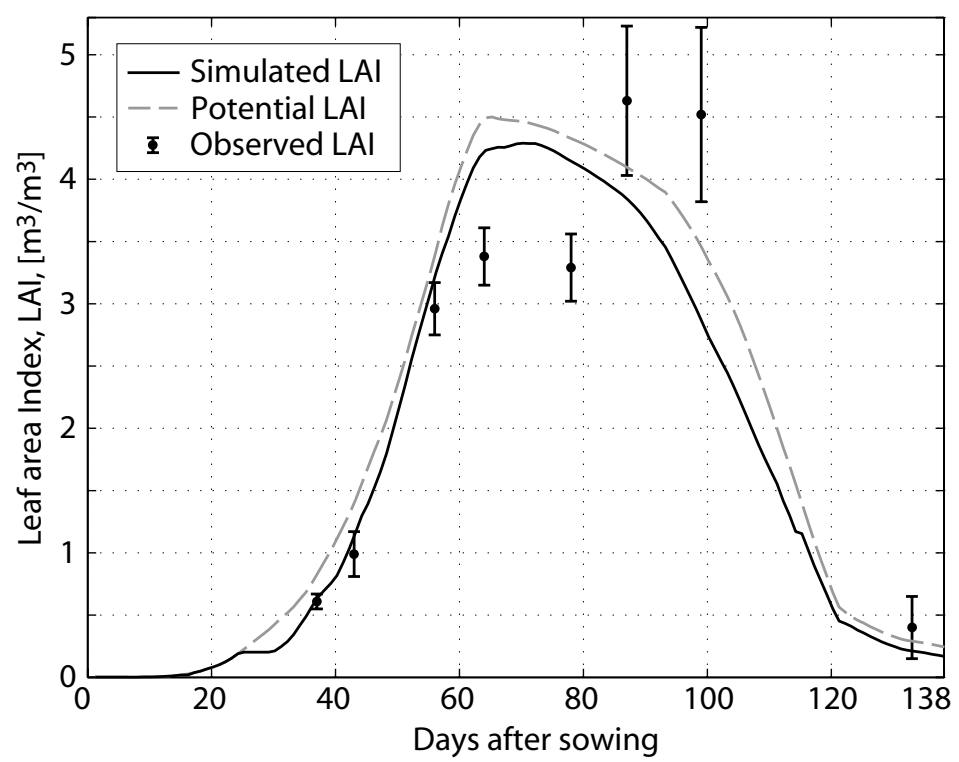

Figure 10: Observed and predicted leaf area index, $L A I$, during the entire growing season of the Lavalette run 
Table 1: Irrigation parameters and furrow geometry parameters of the test runs in the study

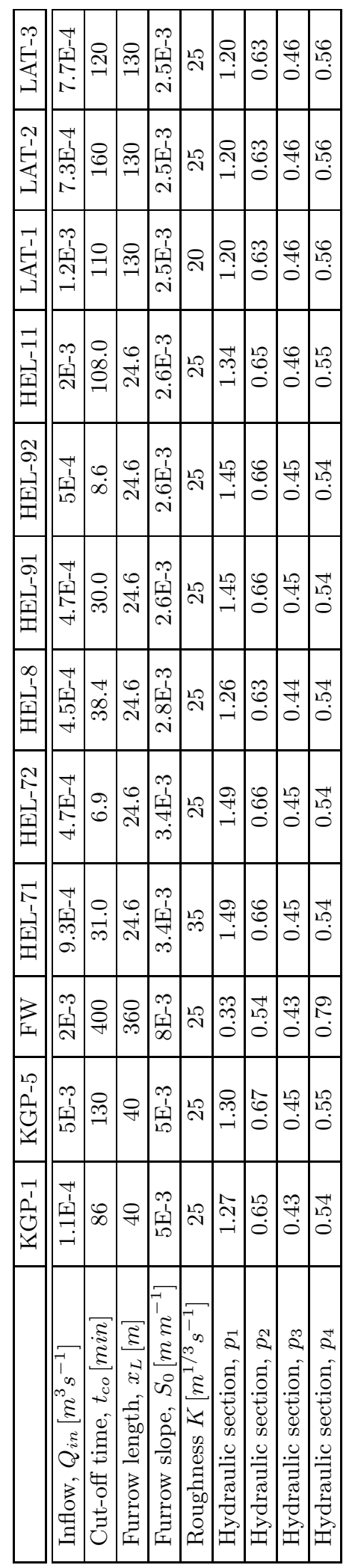


Table 2: Soil hydraulic characteristics of the test runs in the study (KGP .. Kharagpur field experiments, FW .. Flowell-wheel experiments, HEL .. Hubert-Engels-Laboratory experiments, LAT .. Lavalette experiments)

\begin{tabular}{|c|l|l|l|l|l|l|}
\hline Experiment & Layer $[\mathrm{m}]$ & $\theta_{s}$ & $\theta_{r}$ & $\begin{array}{l}\alpha \\
{\left[\mathrm{m}^{-1}\right]}\end{array}$ & $n$ & $\begin{array}{l}K_{s} \\
{\left[\mathrm{~m} \cdot \mathrm{s}^{-1}\right]}\end{array}$ \\
\hline \hline KGP & $0.00-0.15$ & 0.40 & 0.08 & 9.6 & 2.78 & $1.03 \cdot 10^{-5}$ \\
\hline & $0.16-0.30$ & 0.39 & 0.08 & 8.0 & 2.76 & $6.6 \cdot 10^{-6}$ \\
\hline & $0.31-0.45$ & 0.38 & 0.08 & 6.6 & 2.73 & $4.1 \cdot 10^{-6}$ \\
\hline & $0.46-0.60$ & 0.38 & 0.08 & 5.5 & 2.73 & $2.8 \cdot 10^{-6}$ \\
\hline FW & $0.00-0.20$ & 0.39 & 0.04 & 2.0 & 1.45 & $1.8 \cdot 10^{-5}$ \\
\hline & $0.20-1.00$ & 0.39 & 0.04 & 2.0 & 1.45 & $1.4 \cdot 10^{-6}$ \\
\hline HEL & $0.00-1.00$ & 0.39 & 0.07 & 3.93 & 1.64 & $2.05 \cdot 10^{-5}$ \\
\hline LAT & $0.0-0.55$ & 0.35 & 0.05 & 1.5 & 1.46 & $4.2 \cdot 10^{-6}$ \\
\hline & $0.55-0.95$ & 0.38 & 0.05 & 1.3 & 1.45 & $1.4 \cdot 10^{-6}$ \\
\hline & $0.95-2.0$ & 0.41 & 0.05 & 1.9 & 1.31 & $5.2 \cdot 10^{-7}$ \\
\hline
\end{tabular}


Table 3: Initial pressure head conditions for the KGP and HEL experiments

\begin{tabular}{|c|c|c|c|c|c|c|c|c|c|}
\hline Experiment $\backslash$ Depth $[\mathrm{m}]$ & 0.20 & 0.30 & 0.35 & 0.45 & 0.50 & 0.60 & 0.70 & 0.80 & 1.00 \\
\hline \hline KGP-1, $h_{w}$ in $[\mathrm{m}]$ & 0.94 & 0.77 & - & 0.62 & - & 0.51 & - & - & - \\
\hline KGP-5, $h_{w}$ in $[\mathrm{m}]$ & 1.02 & 0.75 & - & 0.55 & - & 0.45 & - & - & - \\
\hline HEL-71, $h_{w}$ in $[\mathrm{m}]$ & 3.54 & 2.64 & 2.08 & 1.12 & 1.27 & 1.01 & 0.54 & 0.37 & 0.11 \\
\hline HEL-8, $h_{w}$ in $[\mathrm{m}]$ & 1.85 & 0.74 & 1.22 & 0.52 & 0.91 & 0.50 & 0.43 & 0.29 & 0.04 \\
\hline HEL-91, $h_{w}$ in $[\mathrm{m}]$ & 1.41 & 0.70 & 1.09 & 0.50 & 0.90 & 0.47 & 0.43 & 0.29 & 0.05 \\
\hline HEL-11, $h_{w}$ in $[\mathrm{m}]$ & 3.00 & 0.87 & 1.48 & 0.74 & 1.03 & 0.55 & 0.71 & 0.46 & 0.03 \\
\hline
\end{tabular}


Table 4: Performance indices for predicted advance and recession times of the Kharagpur (KGP), Flowellwheel (FW) and laboratory (HEL) experiments

\begin{tabular}{|l|r|r|r|}
\hline Experiment & RMSE [min] & $R^{2}$ & $C_{e}$ \\
\hline \hline KGP-1 Advance & 2.3 & 0.99 & 0.70 \\
\hline KGP-1 Recession & 1.7 & 0.51 & -0.10 \\
\hline KGP-5 Advance & 0.3 & 1.00 & 0.92 \\
\hline KGP-5 Recession & 1.2 & 1.00 & 0.74 \\
\hline FW Advance & 9.5 & 0.99 & 0.99 \\
\hline FW Recession & 9.3 & 0.98 & -3.45 \\
\hline HEL 7-1 Advance & 7.1 & 0.99 & 0.97 \\
\hline HEL 7-1 Recession & 27.9 & 0.98 & 0.82 \\
\hline HEL 7-2 Advance & 10.9 & 1.00 & 0.98 \\
\hline HEL 7-2 Recession & 54.0 & 0.96 & 0.72 \\
\hline HEL 9-1 Advance & 48.6 & 0.99 & 0.79 \\
\hline HEL 9-1 Recession & 48.8 & 0.90 & 0.64 \\
\hline HEL 9-2 Advance & 13.2 & 0.99 & 0.93 \\
\hline HEL 9-2 Recession & 36.2 & 0.94 & 0.80 \\
\hline HEL 11 Advance & 4.7 & 1.00 & 0.98 \\
\hline HEL 11 Recession & 30.4 & 0.95 & 0.58 \\
\hline
\end{tabular}




\section{Figure Captions}

\begin{tabular}{|c|l|}
\hline Figure & Caption \\
\hline \hline 1 & Meteorological data observed at the $T a$-plot of the Lavalette site $(1999)$ \\
\hline 2 & Initial soil moisture distribution, as simulated for the day of sowing of the Lavalette run \\
\hline 3 & Observed and simulated advance and recession times for the HEL runs \\
\hline 4 & Observed and simulated advance and recession times for the KGP runs \\
\hline 5 & Observed and simulated advance and recession times for the Flowell-wheel run \\
\hline 6 & $\begin{array}{l}\text { Observed and simulated soil water storage at the upstream section, } x_{i n f}=32.5 \mathrm{~m} \text {, during the } \\
\text { entire } 1999 \text { growing season of corn at Lavalette }\end{array}$ \\
\hline 7 & $\begin{array}{l}\text { Simulated and observed soil moisture profiles at } x=20 \mathrm{~m} / x_{i n f}=32.5 \mathrm{~m} \text { for various times of the } \\
1999 \text { growing season at Lavalette }\end{array}$ \\
\hline 9 & $\begin{array}{l}\text { Simulated soil moisture distribution at } x_{i n f}=32.5 \mathrm{~m} \text { for various times of the } 1999 \text { growing season } \\
\text { at Lavalette }\end{array}$ \\
\hline 10 & $\begin{array}{l}\text { Observed and predicted leaf area index, } L A I, \text { during the entire growing season of the Lavalette } \\
\text { and actual evaporation } E A\end{array}$ \\
\hline
\end{tabular}

